\begin{tabular}{|c|c|c|}
\hline $\begin{array}{l}\text { PKS } \\
\text { PUBLIC } \\
\text { KNOLLEDGE } \\
\text { PROJECT }\end{array}$ & $\begin{array}{c}\text { REVISTA DE GEOGRAFIA } \\
\text { (RECIFE) } \\
\text { http://www.revista.ufpe.br/revistageografia }\end{array}$ & $\begin{array}{l}\text { OJS } \\
\text { OPEEN } \\
\text { JOHNAL } \\
\text { SYSTEMS }\end{array}$ \\
\hline
\end{tabular}

\title{
MINECRAFT COMO FERRAMENTA DE VISUALIZAÇÃO E INTERPRETAÇÃO DA PAISAGEM DE INTERESSE PARA A GEODIVERSIDADE DE MINAS GERAIS - MG
}

\author{
Ítalo Sousa de Sena ${ }^{1}$; Bráulio Magalhães Fonseca ${ }^{2}$; Bruno Amaral de Andrade ${ }^{3}$; \\ Ana Clara Mourão Moura ${ }^{4}$
}

\begin{abstract}
${ }^{1}$ Programa de Pós-Graduação em Geografia - IGC/UFMG e Laboratório de Geoprocessamento da Escola de Arquitetura-GEOPROEA/UFMG. E-mail: italosena@gmail.com

${ }^{2}$ Departamento de Cartografia-IGC/UFMG. E-mail: brauliomagalhaes@gmail.com

${ }^{3}$ Programa de Pós-Graduação em Arquitetura e Urbanismo - EA/UFMG e Laboratório de Geoprocessamento da Escola de Arquitetura-GEOPROEA/UFMG.E-mail: deandradebruno@outlook.com

${ }^{4}$ Departamento de Arquitetura e Urbanismo - EA/UFMG e Laboratório de Geoprocessamento da Escola de Arquitetura-GEOPROEA/UFMG. Email: anaclaramoura@yahoo.com
\end{abstract}

Artigo recebido em 30/11/2017 e aceito em 09/03/2018

\begin{abstract}
RESUMO
A paisagem é composta por uma série de fenômenos e estruturas que se relacionam a partir da troca de energia e matéria. A geodiversidade compõe a porção abiótica deste sistema, dando suporte à vida e às atividades antrópicas. Compreender esta relação possibilita que possamos interagir com a paisagem de forma mais coesa, considerando suas singularidades e seus valores patrimoniais, tal como ocorre com o patrimônio geomorfológico. Esta pesquisa teve como foco a decodificação destes valores paisagísticos sob a ótica da geomorfologia, utilizando o geogame Minecraft, a fim de favorecer a construção de mapas mentais a partir do aprendizado baseado em jogos. A representação da paisagem de forma virtual possibilita decompô-la, evidenciando as parcelas de interesse que a compõe, contribuindo para a percepção dos valores a ela associados. Para tal, foi proposto um roteiro virtual pelas paisagens da Serra do Caraça, Carste de Lagoa Santa e Serra da Canastra a partir do jogo Minecraft.
\end{abstract}

Palavras-chave: Geogame; Exploração; Percepção.

\section{MINECRAFT AS A TOOL FOR VISUALIZATION AND INTERPRETATION OF MINAS GERAIS LANDSCAPES WITH GEODIVERSITY INTEREST - MG}

\begin{abstract}
The landscape is composed by a serie of phenomena and structures that are related from the exchange of energy and matter. Geodiversity composes the abiotic portion of this system, supporting life and human activities. Understanding this relationship allows us to interact with the landscape in a more cohesive way, considering its singularities and heritage values, as is the case with geomorphological heritage. This research focused on the decoding of these landscape values from the viewpoint of geomorphology, using geogame Minecraft, in order to favor the construction of mental maps based on game-based learning. The representation of the landscape in a virtual way makes it possible to decompose it, showing the plots of interest that compose it, contributing to the perception of the values associated with it. For this purpose, a virtual itinerary was proposed for the landscapes of Serra do Caraça, Lagoa Santa Karst and Serra da Canastra using the game Minecraft.
\end{abstract}

Key-words: Geogame; Exploration; Perception. 


\section{INTRODUÇÃO}

A paisagem, como conjunto de formas e processos, pode ser interpretada segundo os fenômenos e estruturas que a compõem, sendo a geodiversidade a parcela referente ao meio abiótico, dando suporte para a vida e atividades antrópicas. Esta apresenta valores a partir dos seus contextos de uso, tais como cultural, didático, turístico, e geoecológicos (geossistemas).

A percepção e compreensão destes valores viabilizam a consciência em relação à diversidade de fenômenos que compõem a paisagem abiótica, bem como a necessidade de conservação de registros destes fenômenos, alcançando caráter geopatrimonial. Na descoberta das paisagens de Minas Gerais o relevo e suas características fisiográficas serviram de base na ocupação do território e exploração dos recursos naturais.

Assim, esta pesquisa tem como objetivo contribuir para a abstração dos valores da geodiversidade que se comunicam com os aspectos sistêmicos da paisagem, a fim de favorecer a percepção da paisagem como herança e patrimônio. Essa percepção da paisagem foi facilitada por meio do uso do jogo Minecraft como um geogame. Para Vemuri, Poplin e Monachesi (2014) geogame é compreendido como um jogo sério com foco na noção espacial e as diferentes formas de representação e visualização de um ambiente.

O termo geogame foi proposto por Schlieder (2014), que defende que o encorajamento da exploração física do território pode ser facilitado por meio do uso de geogames analógicos e digitais.

O Minecraft se apresenta como um jogo com alto potencial de aplicação no ensino baseado em jogos. A Mojang (empresa criadora do jogo) foi comprada pela Microsoft e este iniciou um programa educacional chamada MinecraftEDU (MICROSOFT, 2017), que utiliza a versatilidade do jogo como ferramenta de ensino. Este potencial também é explorado para o planejamento urbano, sendo objeto de estudo por muitos pesquisadores, tal como no GeoCraft (http://geocraft.nl/makingoff/), que consiste em uma plataforma participativa de gestão da paisagem urbana na Holanda (SCHOLTEN, 2017), e o BetterGeo (SGU, 2015), e consiste em um pacote de modificações elaborado para o ensino de geologia.

Para isso, foram modelados no jogo digital Minecraft três cenários de paisagens geodiversas de Minas Gerais, os locais escolhidos foram a Serra do Caraça, Lagoa do Sumidouro e Serra da Canastra, geossítios registrados na SIGEP (Comissão Brasileira de Sítios Geológicos e Paleobiológicos). A Serra do Caraça está inserida na Reserva Particular do Patrimônio Natural Santuário do Caraça. O local apresenta os pontos mais altos do Quadrilátero Ferrífero, além da Gruta do Centenário, cavidade com desenvolvimento linear de 
4.710 metros e um desnível de 484 metros, sendo a maior caverna em rocha quartzítica do mundo (DUTRA et al., 2002).

A geomorfologia da Serra do Caraça é caracterizada principalmente por grandes elevações, com formações constituídas por fraturas e dobras na porção com predominância de quartzitos, apresentando o Pico do Sol com $2.072 \mathrm{~m}$ de altitude e Pico do Inficionado, com $2.068 \mathrm{~m}$ de altitude. A Lagoa do Sumidouro compõe o Parque Estadual do Sumidouro, que integra a Área de Proteção Ambiental Carste de Lagoa Santa. Geomorfologicamente, a porção central da APA Carste de Lagoa Santa compreende a região do médio Rio das Velhas, onde são percebidas formações cársticas expressivas.

Os processos cársticos, associados a outros processos da dinâmica interna e externa, são os principais responsáveis pela evolução de seu relevo (KOHLER, 1989). A Serra da Canastra, que integra a lista dos locais que compõe o Projeto Geoparque do Brasil (SCHOBBENHAUS; SILVA 2012), abriga um parque nacional homônimo. A região sustenta fenômenos geológicos e geomorfológicos relevantes, como intrusões kimberlíticas do Cretáceo Inferior (BENITEZ, 2009), onde a cachoeira Casca D'Anta é o local de maior relevância histórica e geomorfológica, sendo descrita pelo naturalista francês Auguste de Saint- Hilaire, que percorreu a região em 1819 (CHAVES et al., 2008)

\section{MATERIAL E MÉTODOS}

\section{Área de estudo}

A metodologia de pesquisa se deu em três momentos, iniciando pela preparação dos cenários modelados no Minecraft, partindo para uma prática com voluntários, e encerrando com a aplicação de um formulário.

A fim de apresentar a diversidade de paisagens geomorfológicas presentes no Estado de Minas Gerais e avaliar como o Minecraft poderia contribuir para a divulgação das geociências, foram propostos roteiros de exploração em três localidades do estado, que apresentam expressiva geodiversidade e compõem geossistemas específicos.

Os locais escolhidos para serem representados no ambiente virtual do Minecraft foram a Serra do Caraça, Lagoa do Sumidouro e Serra da Canastra. Estes locais foram escolhidos por integrarem a lista de sítios do SIGEP que, até 2012, ano da suspensão das candidaturas, descreveu 116 geossítios, publicados em três volumes, sendo 58 no primeiro, 40 no segundo e 16 no terceiro, além de 49 propostas ainda não publicadas, porém estão disponíveis em formato eletrônico. 
As localidades foram modeladas em três etapas, iniciando pela aquisição de dados, posteriormente a realização de pré-processamento das informações, finalizando com o processo de modelagem do cenário no software WorldPainter.

Para a representação do modelado do relevo no Minecraft foi utilizado como base dados de modelos digitais de elevação (MDE), tal como o SRTM (Shuttle Radar Topographic Mission) da USGS (United States Geological Survey), que é disponibilizado gratuitamente através do portal EarthExplorer. Como o dado de entrada para o WorldPainter é estruturado matricialmente, assim como o Minecraft, é possível utilizar dados georreferenciados processados a partir de técnicas de geoprocessamento.

Os afloramentos rochosos foram representados utilizando a base de imagem do Google Earth, atribuindo à composição do terreno como rochas às áreas com declividade acima de $30^{\circ}$. Para preencher as áreas correspondentes à vegetação com a classe apropriada é possível utilizar várias opções de composição de camadas, no entanto nesta pesquisa utilizouse tanto as camadas de biomas pré-definidas no WorldPainter (Biomas oficiais do Minecraft) quanto objetos Bo2 (arquivos que armazenam design de objetos).

Os arquivos Bo2 foram adquiridos em repositórios compartilhados nas mídias sociais da temática de Minecraft. A prática de exploração da paisagem consistiu em três etapas, iniciando pela apresentação dos locais a serem explorados, seguindo pela exploração e intervenção nas paisagens e concluindo com a aplicação de um formulário de avaliação referente à experiência da prática com o Minecraft.

Os participantes da atividade foram oito alunos voluntários da disciplina de Cartografia e Topografia (CRT 003 e CRT 013) do curso de arquitetura da UFMG, sendo a faixa etária entre 18 e 21 anos de idade, totalizando 4 horas de prática. Os participantes foram distribuídos em computadores para que acompanhassem as orientações da atividade proposta a partir do formulário de avaliação elaborado com o aplicativo Google Form.

Este formulário serviu como roteiro para o desenvolvimento da atividade, onde foram apresentados os conceitos de paisagem, geodiversidade e geossistema, sendo pedido que os participantes escrevessem exemplos que definissem os conceitos apresentados. Para a prática de exploração dos mapas os participantes foram organizados em dois grupos de quatro pessoas, orientados para explorar as paisagens observando as características específicas de cada localidade.

Os roteiros foram estruturados a partir da identificação de marcos geográficos na paisagem, tais como corpos hídricos e terrenos elevados. Ao final foi pedido que os 
participantes propusessem a implementação de edificações e estruturas nos locais, enquanto foram apresentados os contextos de proteção legal e orientações para a construção nestas áreas. No caso dos cenários utilizados nesta prática o contexto de proteção legal se deu pela Lei $n^{\circ} 9.985$ que instituiu o Sistema Nacional de Unidades de Conservação.

\section{RESULTADOS E DISCUSSÕES}

Os cenários foram modelados para o ambiente do Minecraft e foram utilizados pacotes de modificação (mods) para aumentar a experiência da exploração virtual. Foram utilizados dois mods JourneyMAP que adiciona um mapa de navegação e a possibilidade de georreferenciar pontos, e o pacote Shaders Mod que otimiza os gráficos do jogo deixando-os mais próximo da realidade.

Esses recursos contribuíram na interpretação da paisagem, dado que facilitaram a identificação das feições de referência apresentadas nos roteiros de exploração. Os roteiros foram apresentados de forma a indicar um trajeto, indicando o jogador a seguir os pontos notáveis que marcam a paisagem.

Para o primeiro cenário (Fig. 1) o roteiro indicado foi seguir o leito do ribeirão Cascatinha à montante, passando pelo Santuário do Caraça (igreja). Após isso, seguir sentido cachoeira Cascatinha, se orientando a sudeste para acessar o platô da serra, tendo acesso ao pico do Inficionado. O segundo cenário (Fig. 2) foi apresentando a partir do trajeto que partiu do topo maciço do sumidouro, circundando a Lagoa de leste para oeste, alcançando o córrego Samambaia, seguindo o córrego Samambaia à montante, finalizando seguindo para leste até o Rio das Velhas. O terceiro cenário (Fig. 3) iniciou na parte baixa da cachoeira Casca D'anta, seguindo o leito do rio São Francisco à montante, até alcançar a escarpa da Serra da Canastra.

Após isso, foi indicado para que os jogadores seguissem a leste, circundando a escarpa da serra até alcançar a porção norte desta. Encerrando o trajeto seguindo sentido oeste para chegar à nascente do rio São Francisco. Os próprios participantes levantaram a questão de se ocupar as margens dos rios e córregos, da qual foi apresentado o conceito de Área de Preservação Permanente (APP), especificando as metragens de proteção de acordo com o corpo d'água em questão.

A proposição de edificações aconteceu nos cenários da Lagoa do Sumidouro e na Serra da Canastra, e entre as proposições apresentadas pelos participantes estão a implementação de centros de visitantes, locais de mirantes, restaurantes e outros equipamentos voltados para o atendimento de turistas. Durante o roteiro virtual no último 
cenário proposto um dos participantes, ao alcançar a escarpa da Serra da Canastra, comentou que o local parecia a muralha da série de televisão "Game of Thrones", enquanto outro se impressionou com o cenário dizendo "Nossa, que bonito. Isso existe?" se referindo à cachoeira Casca D'anta.

$\mathrm{Na}$ proposta de roteiro foi sugerido aos participantes que navegassem pela área com o foco na visitação turística, considerando que o Parque Nacional pode receber implementação de infraestruturas de acordo com o diagnóstico do Plano de Manejo. Neste contexto surgiram interpretações com relação ao impacto visual de uma edificação próximo a um ponto turístico, e considerações a respeito das áreas de preservação permanente.

Foi sugerido que os participantes consultassem o Google Maps para investigar quais infraestruturas já existem no local, tal como estradas de terra, trilhas e edificações. Ao longo do processo os participantes utilizaram termos como "platô" se referindo à parte alta da Serra da Canastra, a fim de identificar áreas planas para a proposição de um centro de visitantes e um museu. Outro grupo de participantes focou na proposição de infraestrutura para um mirante, com facilidades para os visitantes, tais como restaurante e banheiros.

Entretanto a escolha de um local declivoso para a implantação da edificação resultou num corte e aterro muito abrupto, o que não agradou os participantes (Fig. 4). Ademais, um conceito que norteou as proposições de intervenção foi o cuidado com relação à gentrificação (processo de transformação que descaracteriza o genius loci). Após a realização da prática no Minecraft os participantes retornaram aos computadores para a conclusão do formulário de avaliação. Neste foi perguntado quais das paisagens exploradas o participante já havia estudado a respeito e quais já haviam visitado.

A fim de avaliar a percepção dos participantes com relação à diversidade entre as paisagens visitadas, foram feitas perguntas a respeito do que mais chamou a atenção nas paisagens exploradas, as principais diferenças entre elas, como as características físicas poderiam influenciar na ocupação. Dentre as respostas mais freqüentes nas questões estão as palavras relevo, vegetação, curso d'água e solo, também sendo apresentadas respostas com relação à preservação dos locais e dimensões das feições presentes nos cenários.

Quando perguntados a respeito de como a paisagem poderia influenciar a ocupação, os participantes enfatizaram as questões referentes às limitações de uso presentes na legislação ambiental, tal como as APPs e percentuais de declividade acentuada, além da preocupação com impactos visuais na paisagem. 
Quando perguntados a respeito da alteração de algum dos exemplos dos conceitos de paisagem, geodiversidade e geossistema, nenhum participante respondeu que alteraria, entretanto um dos participantes salientou que poderia melhorar os exemplos e outro respondeu que a experiência com o Minecraft contribuiu para aprimorar o contexto dos conceitos apresentados. Por fim, foram feitas questões referentes ao uso do Minecraft, a fim de avaliar a eficiência do jogo na experiência de exploração virtual.

As perguntas focaram em perceber qual seria o ponto forte da utilização do Minecraft como ferramenta de visualização e exploração da paisagem e qual a principal limitação da utilização do Minecraft, finalizando com a atribuição de uma nota de 0 a 10 para a atividade. Dentre as respostas da primeira questão foram citadas palavras como rapidez na visualização, facilidade na modelagem da paisagem e inserção do espectador, bem como relatos de que a experiência de exploração a partir de um jogo tornou a atividade menos cansativa e mais didática.

Com relação às limitações do uso do Minecraft os participantes salientaram a necessidade de computadores com poder de processamento mais robusto como um fator importante, além de questões como falta de detalhamento devido ao gráfico em blocos e a impossibilidade de ter certas experiências e sensações alcançadas somente com a visitação da paisagem real. Quando perguntados a respeito da nota que daria à experiência no jogo 50\% dos participantes atribuíram nota oito, enquanto $25 \%$ atribuíram nota nove e 10 .

Dentre as respostas referentes às sugestões, os participantes apresentaram os obstáculos na paisagem como um problema (foram inseridos blocos para dificultar o trajeto, a fim tentar reproduzir o atrito da caminhada a pé em um ambiente natural), e a necessidade de inserção das alterações já existentes na paisagem, tais como estradas e áreas já ocupadas. Também foi apresentada a necessidade de gráficos mais realistas para o jogo. 
Figura1- Pico do Inficionado modelado no Minecraft (a), vista da silhueta do 'caraça' e Pico do Inficionado (b) Fonte: http://www.serradocaraca.tur.br.

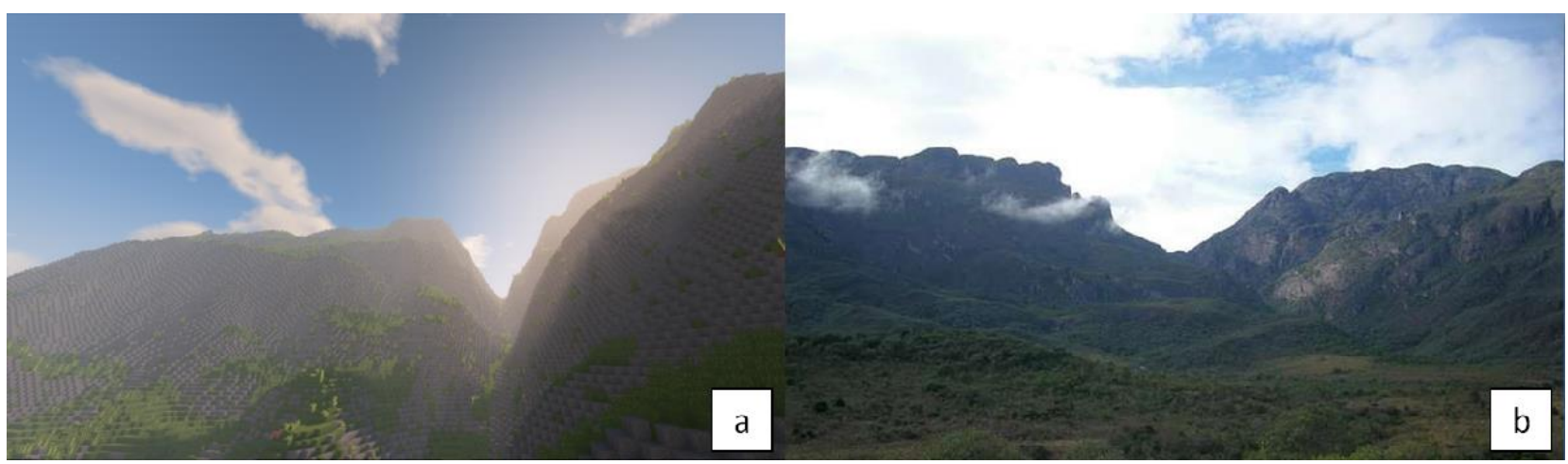

Figura 2 - Maciço do Sumidouro modelado no Minecraft (a), foto do maciço do Sumidouro (b) Fonte: http://www.edhorizonte.com.br.

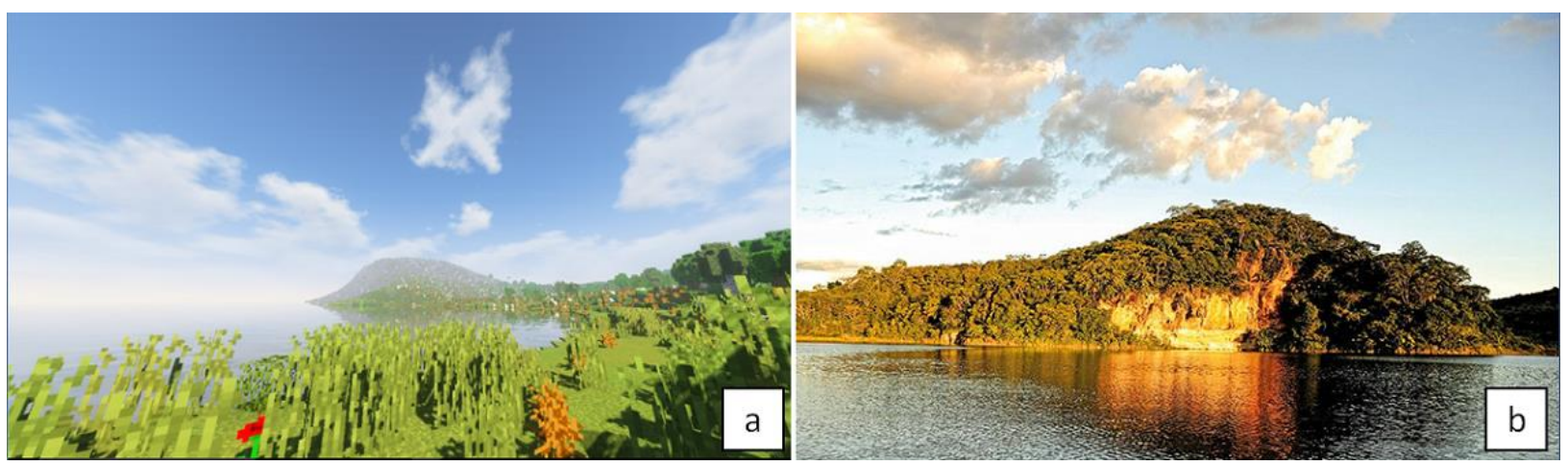

Figura 3- Visualização da Cachoeira Casca D'anta no Minecraft (a), foto da cachoeira Casca D'anta (b) Fonte: https://saiadazonadeconforto.com.br.

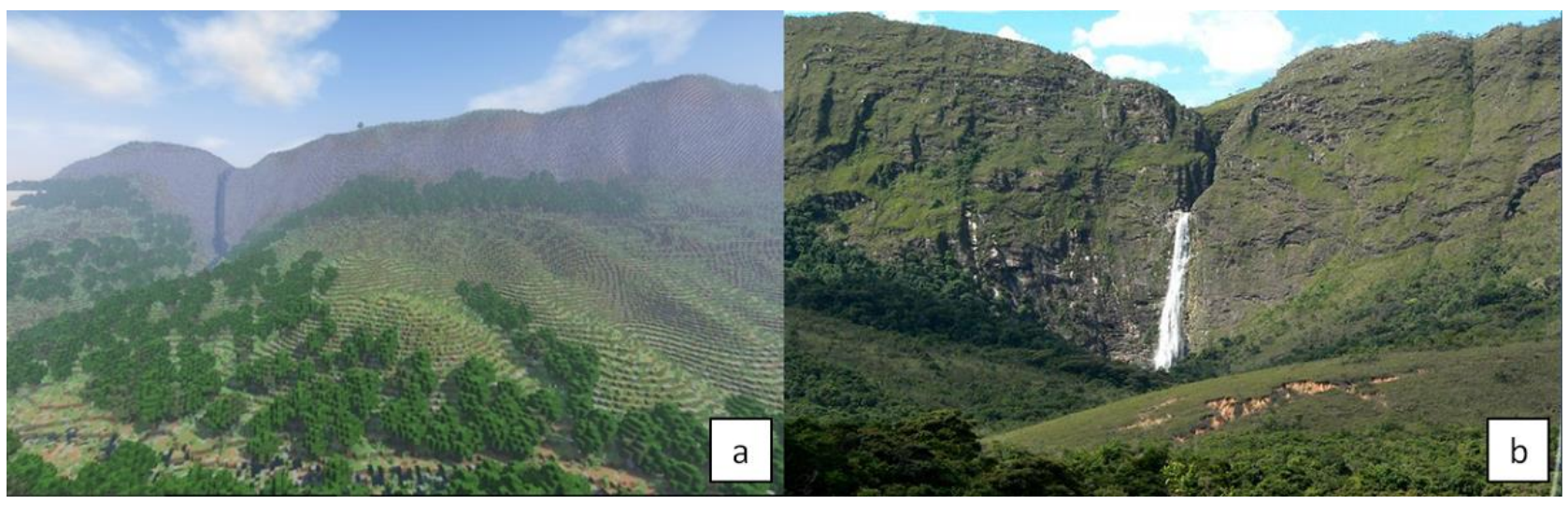


Figura 4 - Participantes inserindo edificação (a), edificação com corte no relevo (b), visualização da edificação com mod JourneyMap (c).

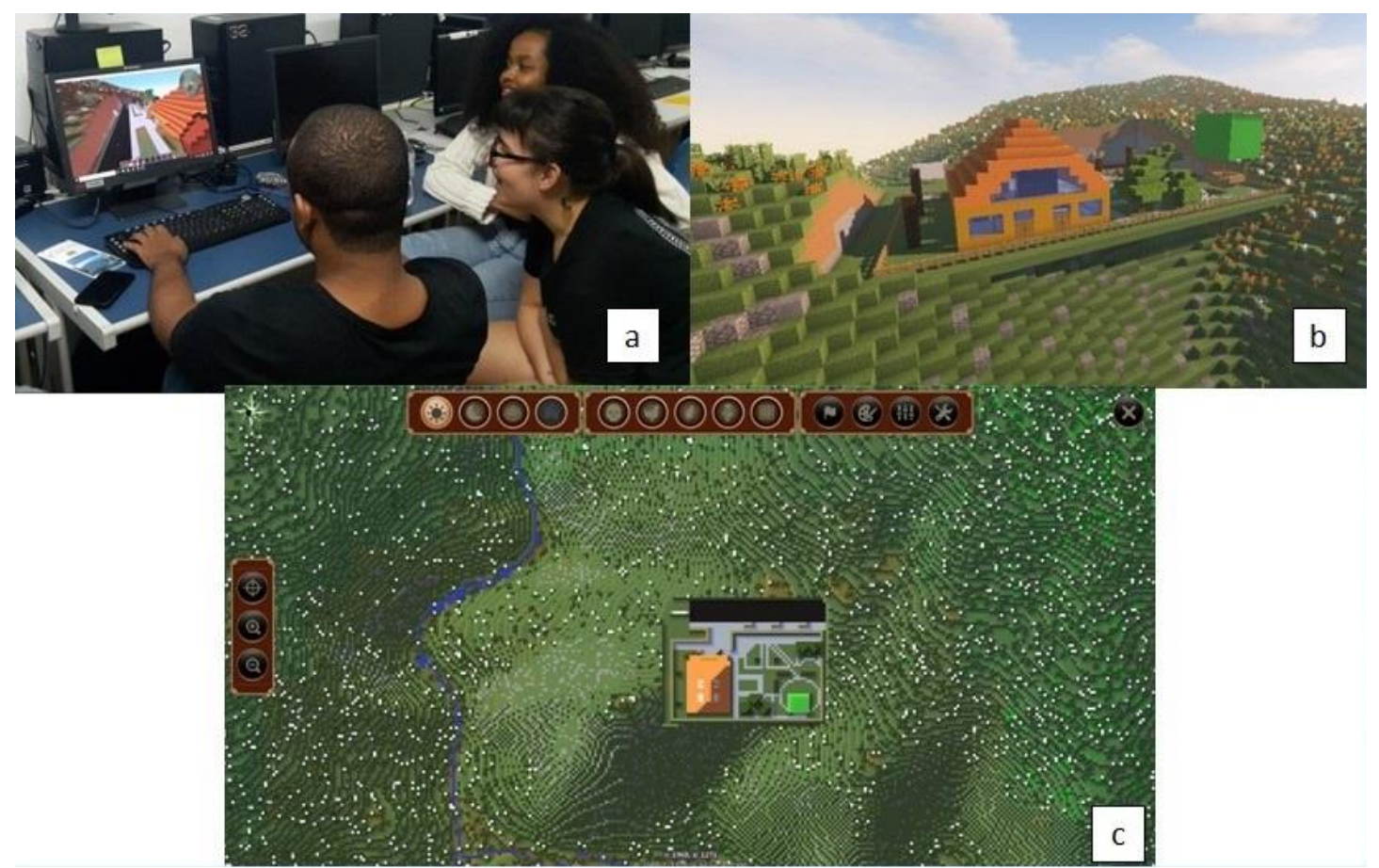

\section{CONSIDERAÇÕES FINAIS}

A utilização do Minecraft como plataforma para a interpretação da paisagem se mostrou capaz de motivar os participantes a perceber as características específicas de cada local, principalmente com relação ao uso e ocupação destas áreas e a diversidade de formas de relevo presentes nos cenários modelados.

A modelagem da paisagem a partir de camadas de informação possibilitou ressaltar os aspectos de interesse, que no caso desta pesquisa as formas de relevo presentes nos três cenários modelados, sendo a Serra do Caraça apresentando um relevo montanhoso, a Lagoa do Sumidouro a depressão cárstica de Lagoa Santa e a Serra da Canastra um relevo escarpado. Além das formas de relevo, o jogo possibilitou a interpretação da rede hídrica dos locais visitados, condicionadas pelas estruturas geomorfológicas.

A proposição de um roteiro virtual a partir de um geogame, partindo da lógica de aprendizado baseado em jogos, ajudou a tornar a atividade mais divertida, dando a possibilidade de trabalhar conceitos complexos como a diversidade geomorfológica e legislações referentes ao uso e ocupação da paisagem de forma descontraída e didática. 
Entretanto é necessário criar o elo entre a visitação virtual e a experiência de visitação real, ampliando a percepção do jogador com relação à composição da paisagem. Assim, esta pesquisa se apresenta como uma proposta inicial da utilização do Minecraft como ferramenta de divulgação das geociências e do patrimônio geomorfológico.

\section{AGRADECIMENTOS}

Os autores agradecem o Conselho Nacional de Desenvolvimento Científico e Tecnológico ( $\mathrm{CNPq}$ ) pelo fomento no projeto intitulado "Geodesign e Modelagem Paramétrica da Ocupação Territorial: Geoprocessamento para a proposição de um Plano Diretor da Paisagem para a região do Quadrilátero Ferrífero-MG", Processo 401066/2016-9, Chamada Universal 1/2016.

\section{REFERÊNCIAS}

BENITEZ, L. Províncias Diamantíferas de Minas Gerais: uma proposta para a caracterização de populações de diamantes típicas como subsídio à Certificação Kimberley. Tese de Doutorado. Universidade Federal de Minas Gerais, Belo Horizonte, Minas Gerais, Brasil. 2009. 254p.

CHAVES, M. L. S. C; BENITEZ, L; ANDRADE, K. W. Cachoeira da Casca D'Anta, São Roque de Minas, MG: berço do Velho Chico, o rio da integração nacional. In: M. Winge; Schobbenhaus, C.; Souza, C.R.G.; Berbert-Born, M.; Queiroz, E.T.; Campos, D.A.. (Org.). Sítios Geológicos e Paleontológicos do Brasil. Brasília: CPRM-SIGEP, 2009, v. 2, p. 151162.

DUTRA, G. M.; RUBBIOLI, E. L.; HORTA, L. S. Gruta do Centenário, Pico do Inficionado (Serra da Caraça), MG: A maior e mais profunda caverna quartzítica do mundo. Schobbenhaus C., Campos DA, Queiroz ET, Winge M., Berbert-Born M. Sítios geológicos e paleontológicos do Brasil, p. 431-441, 2002.

KOHLER, Heinz C. Geomorfologia cárstica na regrau ue lagua santa-MG. São Paulo. FFLCH USP. Departamento de Geografia, p. 113, 1989.

Microsoft. Minecraft Eduwiki. Disponível em: <https://wiki.education.minecraft.net/wiki/main_page//> Acesso em: 05 de dezembro de 2017.

SCHLIEDER, Christoph. Geogames - Gestaltungsaufgaben und Geoinformatische Lösungsansätze. Informatik - Spektrum. V.37, n.6, p. 567 - 574, 2014.

SCHOBBENHAUS, C. SILVA, C.R (Orgs.). Geoparques: propostas do Brasil. Rio de janeiro: CPRM, 2012. $750 \mathrm{p}$.

SCHOLTEN, Henk. Geocraft as a Means to Support the Development of Smart Cities, Getting the People of the place Involved - Youth Included. Quality Innovation Prosperity, v. 21, n. 1, p. $119-150,2017$. 
SGU, Sveriges Geologiska Undersökning. BetterGeo - Minecraft with more geology. Disponível em: <https://www.sgu.se/en/geology-of-sweden/bettergeo-minecraft-with-moregeology/> Acesso em: 05 de dezembro de 2017

VEMURI, Kavita; POPLIN, Alenka; MONACHESI, Paola. YouPlaceIt!: A Serious Digital Game for Achieving Consensus in Urban Planning. In: 17th AGILE Conference on Geographic Information Science (AGILE), Workshop Geogames and Geoplay, Castellón, Spain. 2014. 